\title{
Vocabulary Subtest (WISC-V)
}

National Cancer Institute

\section{Source}

National Cancer Institute. Vocabulary Subtest (WISC-V). NCI Thesaurus. Code C120361.

A subtest of the Wechsler Intelligence Scale for Children, Fifth Edition. The subject either names objects presented visually or defines words that are presented visually and orally. 